\title{
History of Endoscopic Spine Surgery in India
}

\author{
Jitin Bajaj1,๑ Yad Ram Yadav ${ }^{1, \odot}$ \\ ${ }^{1}$ Department of Neurosurgery, NSCB Medical College, Jabalpur, \\ Madhya Pradesh, India
}

\begin{abstract}
Address for correspondence Yad Ram Yadav, MCh, Department of Neurosurgery, and Director Superspeciality Hospital, NSCB Medical College, Jabalpur, Madhya Pradesh, India (e-mail: yadavyrns@gmail.com).
\end{abstract}

\author{
Abstract \\ Keywords \\ - Minimally invasive \\ surgical procedures \\ - Neuroendoscopy \\ - Spinal cord
}

Endoscopic spine surgeries provide distinct advantages and is therefore a viable alternative to open or microscopic techniques. Indian surgeons have shown their expertise from craniovertebral junction to lumbosacral spine with these techniques. Many novel approaches like endoscopic transcervical, partial corpectomy, and others have been designed, and many technological innovations for these surgeries have been made. With different training programs attracting both native and international surgeons, the future of endoscopic spine surgery is bright.

\section{Introduction}

Endoscopic spine surgery has proved to be a viable alternative to open or microscopic surgery. ${ }^{1,2}$ It provides the advantages of minimal invasiveness, panoramic vision, short hospital stay, and reduced blood loss. Indian surgeons have earned both technical and technological expertise in this field. These include being involved in the implementation of novel approaches from craniocervical to the lumbosacral junction, and the development of new instruments. The endoscopic era started two decades back, and it is still scaling new heights. This review highlights the rich history of endoscopic spine surgery in India.

\section{Methodology}

A Pubmed search using keywords: "Neuroendoscopy;" "Endoscopic Spine India[ad]"; "Endoscopic Craniovertebral Junction India[ad]"; "Endoscopic Lumbar disc"; "Endoscopic Cervical disc"; Endoscopic Thoracic disc"; "Endoscopic spinal neoplasm India[ad]"; "Endoscopic Chiari malformation India[ad]" was done. It revealed 272 results, of which 53 articles were found to be relevant. All articles belonged to English literature.

\section{Endoscopic Interlaminar Approach to Lumbar Disc}

The earliest evidence of published endoscopic spine literature from India is by Husain et al in 2005. ${ }^{3}$ They developed a conical tube for the interlaminar approach to herniated lumbar discs, and showed $90 \%$ excellent results at L1-2 to L5-S1 disc levels. ${ }^{3}$ Similarly, Ranjan et al published their results of 107 lumbar discs at L4-5 or L5-S1 by introducing the endoscope through the Medtronic tubular system. The success rate was $92.4 \%$ with a $6.5 \%$ complication rate. ${ }^{4}$ Jhala et al also reported encouraging results. ${ }^{5}$ Kaushal et al with a series of 300 patients published the use of the Destandau system in India, showing good results in 90\% of patients. ${ }^{6}$ The 2011 randomized controlled trial by Garg et al between microendoscopic and open lumbar discectomy was the first class 1 evidence for endoscopic spine surgeries from India. They showed reduced hospital stay and blood loss in the microendoscopic group, however, the operative time was longer. The improvement was similar in both groups. ${ }^{2}$ Yadav et al in 2013 published a series of 400 single or double-level lumbar discectomy with unilateral or bilateral symptoms of central, sequestrated, or migrated disc using the Destandau system. They showed 91\% good-to-excellent results using published online January 13, 2022
DOI https://doi.org/ $10.1055 / \mathrm{s}-0041-1730872$ ISSN 2277-954X (c) 2022. Neurological Surgeons' Society of India.

This is an open access article published by Thieme under the terms of the Creative Commons Attribution-NonDerivative-NonCommercial-License, permitting copying and reproduction so long as the original work is given appropriate credit. Contents may not be used for commercial purposes, or adapted, remixed, transformed or built upon. (https://creativecommons.org/licenses/by-nc-nd/4.0/).

Thieme Medical and Scientific Publishers Pvt. Ltd. A-12, 2nd Floor, Sector 2, Noida-201301 UP, India 
the McNab criteria with a follow-up ranging from 10 months to 5 years. ${ }^{7,8}$ Later, other authors including Wani et al from Sher-i-Kashmir Institute of Medical Sciences and other centers also showed excellent outcomes with microendoscopic techniques. ${ }^{9-14}$ Innovative methods like the use of a knee-joint arthroscope for lumbar discs by Kaushal et al and the development of indigenous endoscopic discectomy set: "Endospine plus" by Chhabra et al have proved useful and reduced the costs of these procedures. ${ }^{15,16}$

\section{Endoscopic Approaches to Lumbar Canal Stenosis}

Yadav et al successfully showed endoscopic multilevel decompression of the lumbar canal after endoscopic decompression, using a unilateral approach. They showed significant improvement in various canal diameters after surgeries such as anteroposterior diameter ( $4.75 \pm 1.75 \mathrm{~mm}$ to 10.33 $\pm 2.11 \mathrm{~mm})$, interfacet distance $(12.70 \pm 4.86 \mathrm{~mm}$ to 18.92 $\pm 3.53 \mathrm{~mm})$, and canal surface area $\left(76.45 \pm 25.36 \mathrm{~mm}^{2}\right.$ to $187.13 \pm 41.04 \mathrm{~mm}^{2}$ ). Of the total, $90 \%$ of the patients showed excellent clinical improvement. ${ }^{17,18}$

\section{Endoscopic Transforaminal Lumbar Discectomy}

This technique was pioneered in India by Dr. Gore. He along with Yeung in 2011 showed in vivo pathoanatomy of intradiscal, foraminal, and central disc herniations by the transforaminal technique. ${ }^{19}$ They further went on to show endoscopic foraminal and dorsal rhizotomy for chronic axial back pain in 450 patients with good results. ${ }^{20}$ Later, they also utilized this technique for failed back surgery syndrome. ${ }^{21}$ High-intensity zone lesions in lumbar discs as a pain generator was described by Gore's group and reported good results using the transforaminal technique. ${ }^{22}$ The technique provided benefits of a natural route, the Kambin's triangle, and avoiding the violation of any bony structures (lamina, facets). The ability of this technique to be performed under local anesthesia was an added advantage. ${ }^{23}$ Good results of this technique were also shown by other authors subsequently. ${ }^{24}$ Decompression of canal stenosis is difficult and is a critical limitation of this technique.

\section{Endoscopic Aspiration and Biopsy of Tubercular Lumbar Spondylodiskitis}

In a series of 18 patients with intractable back pain, Pawar et al used the percutaneous transforaminal technique for aspiration and biopsy of the lumbar epidural abscess. The pain scores improved in all the patients and there was no recurrence after chemotherapy. ${ }^{25}$

\section{Thoracoscopic Decompression of Tubercular Spondylitis}

Thoracoscopy is a minimally invasive technique to deal with anterior and middle columns of dorsal vertebrae pathologies. Kapoor et al, in 2005, achieved good neurologic recovery by decompressing the tubercular thoracic spine with the help of video-assisted thoracoscopy in 14 out of 16 patients. ${ }^{26}$ The thoracoscopic approach was shown to be a viable alternative to open thoracotomy. Later, Jayaswal et al combined debridement with fusion in such cases. The anterior column was reconstructed with either a rib graft or titanium mesh cage. ${ }^{27}$ In 2012, Kapoor et al published their long-term follow-up (60-90 months) in 30 patients with return of neurological functions and ambulatory power in all patients. ${ }^{28}$

\section{Endoscopy for Cervical Disc Disease}

Yadav et al introduced this approach in India in 2014. In a prospective series of 50 patients of monosegmental soft or hard disc causing radiculomyelopathy, the pain scores and Nurick grading were shown to improve with no permanent complication or mortality. ${ }^{29}$ Later, they also published two-level disc surgeries with a technique of disc-preservation. ${ }^{30}$ Percutaneous endoscopic cervical discectomy in India was started by Nadkarni et al. On 20 patients, with a follow-up of 6 months, they reported good pain relief and favorable functional outcome. It was performed as stitchless day care surgery. ${ }^{31}$

\section{Endoscopic Cervical Corpectomy}

Endoscopic partial corpectomy was first described by Yadav et al. The procedure aims to partially remove the vertebral body without the need for fusion, thereby possibly avoiding the complications of a fusion procedure. The procedure is indicated when the compressive element is posterior to the body and also when the disc is significantly migrated behind the vertebral body. ${ }^{32}$

\section{Endoscopic Posterior Approach for Cervical Spondylotic Myelopathy}

The endoscopic approach for cervical spondylotic myelopathy avoids damage of supraspinous ligaments and preserves one-sided paraspinal musculature. This is critical for reducing pain and stability. Yadav et al first performed endoscopic hemilaminectomies and laminoforaminotomies for cervical spondylotic myelopathy in India. ${ }^{33}$ In a prospective series of 50 patients, they showed good results with no permanent complications. The approach is particularly useful for multilevel cervical myelopathy.

\section{Endoscopic Approach for Chiari Malformation}

Ratre et al first published the Indian study of an endoscopic approach for Chiari I malformation with or without syrinx. Endoscopic suboccipital drilling of approximately $3 \mathrm{~cm}$ bone along with laminectomy of atlas and partial splitting of dura showed improvement in 15 patients. It is a safe and effective alternative to microsurgical management. ${ }^{34}$ 


\section{Endoscopy for Spinal Tumors}

Endoscopic excision is possible for both intradural and extradural spinal tumors, although requiring a steep learning curve. Kulkarni et al published a C2 lamina-lateral mass complex osteoid osteoma operated by microendoscopic technique. The tumor was removed completely with improvement in pain and neck disability index at a 1-year follow-up..$^{35}$ Parihar et al reported 18 intradural extramedullary tumors of cervical, thoracic, and lumbar levels using the Destandau system and showed clinical improvement in all patients. The hemostasis and dural closure required experience. $^{36}$ Similarly, Dhandapani et al reported similar outcomes in 16 intradural tumors, including at craniovertebral junction. ${ }^{37}$ Degenerative epidural cysts can also be effectively treated by minimally invasive endoscopic means. ${ }^{38}$

\section{Endoscopic Approaches for Irreducible Atlantoaxial Dislocation (AAD)}

The minimal invasiveness of endoscopic surgeries obviates excessive retraction of critical structures. Endoscopic transoral odontoid excision was first reported in India by Husain et al in 2006. ${ }^{39}$ Yadav et al, in 34 patients of irreducible AAD, showed safety and efficacy of this technique without palatal splitting, even in patients with small oral openings. ${ }^{40-42}$ Later, they described both anterior decompression and fusion using transoral approach with good outcome. ${ }^{43}$ Nagpal published a report of transnasal endoscopic removal of odontoid for severe basilar invagination. ${ }^{44}$ Similar endoscopic transnasal approach was reported by Deopujari et al in $2014 .{ }^{45}$ Overall, if the majority of lesion is above the hard palate, one should use transnasal route, and when it is between the palate and mandible, transoral approach provides direct trajectory. Yadav et al used combined fusion with decompression in irreducible AAD cases, utilizing a single-stage transcervical endoscopic approach. In a series of 10 patients, they showed its safety and good efficacy. A sterile route, compared with transnasal and transoral, single stage decompression and fusion, and minimal invasiveness were its advantages. ${ }^{46,47}$

\section{Exoscope}

Exoscope is a device, which has a long focal length. The device is a bridge between an endoscope and a microscope and can be used to learn endoscopic skills. It also adds to the surgeon's comfort compared with a microscope. Parihar et al used the exoscope in both cranial and spinal procedures with good outcomes. ${ }^{48}$

\section{Endoscopic Training}

As endoscopy has a steep learning curve, one has to learn adequately to avoid complications. Live operative workshops and cadaver training are invaluable tools for this. A big impetus to the endoscopic training in India has been given by the neuroendoscopy fellowship program by Prof. YR Yadav. It has trained more than 600 surgeons from India and abroad.
Other good endoscopic spine training programs are by Prof. Gore, Prof. Deopujari, and Dr. Rohidas. In addition to live and cadaver programs, one can also practice on indigenous hands-on models. ${ }^{49}$

\section{Conclusion}

Indian surgeons have made both technical and technological innovations in the endoscopic spine field. The surgeries have proved to be better or a viable alternative to open or microscopic techniques. Many different training programs provide a bright future for the younger generation.

\section{Conflict of Interest}

None declared.

\section{References}

1 Yadav YR, Parihar V, Kher Y, Bhatele PR. Endoscopic inter laminar management of lumbar disease. Asian J Neurosurg 2016;11(1):1-7

2 Garg B, Nagraja UB, Jayaswal A. Microendoscopic versus open discectomy for lumbar disc herniation: a prospective randomised study. J Orthop Surg (Hong Kong) 2011;19(1):30-34

3 Husain M, Jha DK, Agrawal S, Husain N, Gupta RK. Conical working tube: a special device for endoscopic surgery of herniated lumbar discs. J Neurosurg Spine 2005;2(3):265-270

4 Ranjan A, Lath R. Microendoscopic discectomy for prolapsed lumbar intervertebral disc. Neurol India 2006;54(2):190-194

5 Jhala A, Mistry M. Endoscopic lumbar discectomy: experience of first 100 cases. Indian J Orthop 2010;44(2):184-190

6 Kaushal M, Sen R. Posterior endoscopic discectomy: results in 300 patients. Indian J Orthop 2012;46(1):81-85

7 Yadav YR, Parihar V, Namdev H, Agarwal M, Bhatele PR. Endoscopic interlaminar management of lumbar disc disease. J Neurol Surg A Cent Eur Neurosurg 2013;74(2):77-81

8 Dubey A, Yadav N, Ratre S, Parihar VS, Yadav YR. Lumbar microendoscopic discectomy: clinical results of 920 patients. J Spinal Surg. 2018;5(1):23-28

9 Kulkarni AG, Bassi A, Dhruv A. Microendoscopic lumbar discectomy: technique and results of 188 cases. Indian J Orthop 2014;48(1):81-87

10 Bhaisare R, Kamble B, Patond K. Long-term results of endoscopic lumbar discectomy by "Destandau's technique" Asian Spine J 2016;10(2):289-297

11 Soman SM, Modi JV, Chokshi J. Feasibility of endoscopic discectomy by inter laminar approach at a high volume tertiary public hospital in a developing country. J Spine Surg 2017;3(1):38-43

12 Marappan K, Jothi R, Paul Raj S. Microendoscopic discectomy (MED) for lumbar disc herniation: comparison of learning curve of the surgery and outcome with other established case studies. J Spine Surg 2018;4(3):630-637

13 Dey PC, Nanda SN. functional outcome after endoscopic lumbar discectomy by Destandau's technique: a prospective study of 614 patients. Asian Spine J 2019;13(5):786-792

14 Wani A, Thoker A, Arif S, Malik N, Ramzan A. Endoscopic lumbar discectomy: experience of first 32 cases. JK Pract 2019;24(3-4):19-22

15 Kaushal M. Results of arthrospine assisted percutaneous technique for lumbar discectomy. Indian J Orthop 2016;50(3):228-233

16 Chhabra SS, Sharma D, Gupta A. How I do it? Endoscopic discectomy using a new trocar "Endospine Plus" for lumbar prolapsed intervertebral disc. Acta Neurochir (Wien) 2019;161(11):2369-2373 
17 Dewanngan NK, Yadav YR, Parihar VS, Ratre S, Kher Y, Bhatele P. Extent of decompression of lumbar spinal canal after endoscopic surgery. J Neurol Surg A Cent Eur Neurosurg 2017;78(6):541-547

18 Yadav YR, Yadav N, Parihar V, Kher Y, Ratre S. Endoscopic posterior decompression of lumbar canal stenosis. Indian J Neurosurg. 2013;02(2):124-130

19 Yeung AT, Gore S. In-vivo endoscopic visualization of patho-anatomy in symptomatic degenerative conditions of the lumbar spine II: intradiscal, foraminal, and central canal decompression. Surg Technol Int 2011;21:299-319

20 Yeung A, Gore S. Endoscopically guided foraminal and dorsal rhizotomy for chronic axial back pain based on cadaver and endoscopically visualized anatomic study. Int J Spine Surg 2014;8:23

21 Yeung A, Gore S. Endoscopic foraminal decompression for failed back surgery syndrome under local anesthesia. Int J Spine Surg 2014;8:22

22 Namboothiri S, Gore S, Veerasekhar G. Treatment of low back pain by treating the annular high intensity zone (HIZ) lesions using percutaneous transforaminal endoscopic disc surgery. Int J Spine Surg 2018;12(3):388-392

23 Gore S, Yeung A. The "inside out" transforaminal technique to treat lumbar spinal pain in an awake and aware patient under local anesthesia: results and a review of the literature. Int J Spine Surg 2014;8:28

24 Gotecha S, Ranade D, Patil SV, et al. The role of transforaminal percutaneous endoscopic discectomy in lumbar disc herniations. J Craniovertebr Junction Spine 2016;7(4):217-223

25 Pawar A, Manwani C, Thete R, Bapat M, Peshettiwar V, Gore S. Endoscopic decompression can be effective for diagnosing and treating tubercular spondylodiskitis with early epidural spinal compression: a retrospective study of 18 cases. Asian Spine J 2018;12(5):803-809

26 Kapoor SK, Agarwal PN, Jain BKJr, Kumar R. Video-assisted thoracoscopic decompression of tubercular spondylitis: clinical evaluation. Spine 2005;30(20):E605-E610

27 Jayaswal A, Upendra B, Ahmed A, Chowdhury B, Kumar A. Video-assisted thoracoscopic anterior surgery for tuberculous spondylitis. Clin Orthop Relat Res 2007;460(460):100-107

28 Kapoor S, Kapoor S, Agrawal M, Aggarwal P, Jain BKJr. Thoracoscopic decompression in Pott's spine and its long-term follow-up. Int Orthop 2012;36(2):331-337

29 Yadav YR, Parihar V, Ratre S, Kher Y. Endoscopic anterior decompression in cervical disc disease. Neurol India 2014;62(4):417-422

30 Parihar VS, Yadav N, Ratre S, Dubey A, Yadav YR. Endoscopic anterior approach for cervical disc disease (disc preserving surgery) World Neurosurg 2018;115:e599-e609

31 Nadkarni SM, Kohli P, Patel B, Gore S, Kulkarni BS. STITCHLESS Percutaneous Endoscopic Cervical Discectomy: Are We Moving Towards Day Care Discectomy Procedure? Indian J Orthop 2017;51(6):653-657

32 Yadav YR, Ratre S, Parihar V, Dubey A, Dubey MN. Endoscopic partial corpectomy using anterior decompression for cervical myelopathy. Neurol India 2018;66(2):444-451

33 Yadav YR, Parihar V, Ratre S, Kher Y, Bhatele PR. Endoscopic decompression of cervical spondylotic myelopathy using posterior approach. Neurol India 2014;62(6):640-645
34 Ratre S, Yadav N, Yadav YR, Parihar VS, Bajaj J, Kher Y. Endoscopic management of Arnold-Chiari malformation type i with or without syringomyelia. J Neurol Surg A Cent Eur Neurosurg 2018;79(1):45-51

35 Kulkarni AG, Dhruv AN, Bassi AJ. Microendoscopic excision of C2 osteoid osteoma: a technical report. Spine 2013;38(19):E1231-E1234

36 Parihar VS, Yadav N, Yadav YR, Ratre S, BajajJ, Kher Y. Endoscopic management of spinal intradural extramedullary tumors. J Neurol Surg A Cent Eur Neurosurg 2017;78(3):219-226

37 Dhandapani S, Karthigeyan M. "Microendoscopic" versus "pure endoscopic" surgery for spinal intradural mass lesions: a comparative study and review. Spine J 2018;18(9):1592-1602

38 Kim H-S, Singh R, Adsul N, Bang J-S, Park C-H, Jang I-T. Full endoscopic treatment of unusual spontaneous degenerative epidural cyst: A case report. Surg Neurol Int 2019;10:58

39 Husain M, Rastogi M, Ojha BK, Chandra A, Jha DK. Endoscopic transoral surgery for craniovertebral junction anomalies. Technical note. J Neurosurg Spine 2006;5(4):367-373

40 Yadav YR, Madhariya SN, Parihar VS, Namdev H, Bhatele PR. Endoscopic transoral excision of odontoid process in irreducible atlantoaxial dislocation: our experience of 34 patients. J Neurol Surg A Cent Eur Neurosurg 2013;74(3):162-167

41 Yadav Y, Parihar V, Ratre S, Endoscopic Transoral Odontoidectomy. In: Federico AL and Eduardo V, eds. Frontiers in Neurosurgery: Video Atlas of Spine Surgical Techniques. Vol 2. Sharjah: Bentham Science Publishers; 2016: 25-32

42 Yadav Y, Shenoy R, Mukerji G, Sherekar S, Parihar V, Endoscopic transoral excision of odontoid process in irreducible atlanto-axial dislocation. In: Deepu B, Apoorva P, eds. Progress in Clinical Neurosciences. Vol 24. Delhi: Byword Books Private Limited and Neurological Society of India; 2010 159-169

43 Yadav YR, Parihar VS, Ratre S, Dubey A, Jindel S, Dubey MN. Endoscopic single stage trans-oral decompression and anterior C1 lateral mass and C2 pedicle stabilization for atlanto-axial dislocation. Neurol India 2019;67(2):510-515

44 Nagpal T. Transnasal endoscopic removal of malformation of the odontoid process in craniovertebral anomaly: a case report. Kulak Burun Bogaz Ihtis Derg 2013;23(2):123-126

45 Deopujari CE, Karmarkar VS, Shah NJ. Endoscopic approaches to the craniovertebral junction and odontoid process. World Neurosurg 2014;82(6(Suppl):S49-S53

46 Yadav YR, Ratre S, Parhihar V, Dubey A, Dubey NM. Endoscopic technique for single-stage anterior decompression and anterior fusion by transcervical approach in atlantoaxial dislocation. Neurol India 2017;65(2):341-347

47 Swamy M, Yadav Y, Parihar V, et al. Endoscopic transcervical approach to craniovertebral junction. In: Yadav YR, Sharma BS, Bajaj J, eds. Neuroendoscopic Surgery: A Comprehensive Approach. 1st ed. Noida: Salubris Medical Publishers; 2020 378-382

48 Parihar V, Yadav YR, Kher Y, Ratre S, Sethi A, Sharma D. Learning neuroendoscopy with an exoscope system (video telescopic operating monitor): early clinical results. Asian J Neurosurg 2016;11(4):421-426

49 Bajaj J, Yadav YR, Pateriya A, Parihar V, Ratre S, Dubey A. Indigenous inexpensive practice models for skill development in neuroendoscopy. J Neurosci Rural Pract 2017;8(2):170-173 